\title{
Postoperative cerebral oxygenation was not associated with new brain injury in infants with congenital heart disease
}

\author{
Nathalie H. P. Claessens, MD, PhD, ${ }^{\mathrm{a}, \mathrm{b}, \mathrm{c}}$ Nicolaas J. G. Jansen, MD, PhD, \\ Johannes M. P. J. Breur, MD, PhD, ${ }^{b}$ Selma O. Algra, MD, PhD,${ }^{d}$ Raymond Stegeman, MD, \\ Thomas Alderliesten, MD, PhD, ${ }^{a}$ Kim van Loon, $\mathrm{MD}, \mathrm{PhD},{ }^{\mathrm{e}}$ Linda S. de Vries, $\mathrm{MD}, \mathrm{PhD},{ }^{\mathrm{a}}$ \\ Felix Haas, MD, PhD, ${ }^{\mathrm{f}}$ Manon J. N. L. Benders, MD, PhD, ${ }^{a}$ and Petra M. A. Lemmers, MD, PhD
}

\section{ABSTRACT}

Objective: The aim of this study was to evaluate postoperative indices of cerebral oxygenation and autoregulation in infants with critical congenital heart disease in relation to new postoperative ischemic brain injury.

Methods: This prospective, clinical cohort included 77 infants with transposition of the great arteries $(\mathrm{N}=19)$, left ventricular outflow tract obstruction $(\mathrm{N}=30)$, and single ventricle physiology $(\mathrm{N}=28)$ undergoing surgery at 30 days or less of life. Postoperative near-infrared spectroscopy and physiologic monitoring were applied to extract mean arterial blood pressure, regional cerebral oxygen saturation, fractional tissue oxygen extraction, and regional cerebral oxygen saturation mean arterial blood pressure correlation coefficient $(\geq 0.5$ considered sign of impaired cerebral autoregulation). New postoperative ischemic injury was defined as moderate-severe white matter injury or focal infarction on magnetic resonance imaging. Low cardiac output syndrome was measured as lactate greater than $4 \mathrm{mmol} / \mathrm{L}$ with $\mathrm{pH}$ less than 7.30 .

Results: After surgery, regional cerebral oxygen saturation was decreased in all congenital heart disease groups with a notable increase in regional cerebral oxygen saturation between 6 and 12 hours after surgery, on average with a factor of 1.4 (range, 1.1-2.4). Both single ventricle physiology and postoperative low cardiac output syndrome were associated with lower regional cerebral oxygen saturation and increased time with correlation coefficient of 0.5 or greater. New postoperative ischemic injury was seen in 39 patients $(53 \%)$ and equally distributed across congenital heart disease groups. Postoperative regional cerebral oxygen saturation, fractional tissue oxygen extraction, and correlation coefficient were not independently associated with new postoperative white matter injury or focal infarction (mixed-model analysis, all $\mathrm{F}>0.12$ ).

Conclusions: Postoperative indices of cerebral oxygenation and cerebral autoregulation are not independent predictors of new ischemic brain injury in infants with critical congenital heart disease. Further exploration of the complex interplay among low regional cerebral oxygen saturation, low cardiac output syndrome, and heart defect is required to identify potential biomarkers enabling early intervention for ischemic brain injury. (J Thorac Cardiovasc Surg 2019;158:867-77)

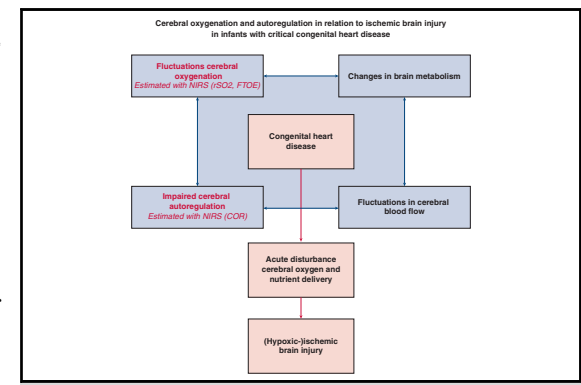

Graphical model for brain circulation and ischemic brain injury in infants with critical CHD. Multiple factors with a complex interaction play a role in optimal brain hemodynamics and the potential association with ischemic brain injury.

\section{Central Message}

Postoperative indices of cerebral oxygenation and autoregulation measured by NIRS do not independently predict new ischemic brain injury in infants with critical CHD.

\section{Perspective}

Infants with critical CHD are at risk of postoperative ischemic brain injury, and early postoperative biomarkers will enable early interventions. Postoperative indices of cerebral oxygenation and autoregulation do not independently predict new ischemic brain injury in a clinical, prospective cohort of infants with different types of CHD.

See Commentaries on pages 878 and 880 .

\footnotetext{
From the Departments of ${ }^{\mathrm{a}}$ Neonatology, ${ }^{\mathrm{b}}$ Pediatric Cardiology, ${ }^{\mathrm{c}}$ Pediatric Intensive Care, and ${ }^{\mathrm{f} P e d i a t r i c}$ Cardiothoracic Surgery, Wilhelmina Children's Hospital, University Medical Center Utrecht, Utrecht, The Netherlands; and Departments of ${ }^{\mathrm{d}}$ Radiology and ${ }^{\mathrm{e}}$ Anesthesiology, University Medical Center Utrecht, Utrecht, The Netherlands.

Received for publication Sept 23, 2018; revisions received Feb 10, 2019; accepted for publication Feb 24, 2019; available ahead of print April 11, 2019.
}

\footnotetext{
Address for reprints: Nathalie H. P. Claessens, MD, PhD, Department of Neonatology, University Medical Center Utrecht, Location Wilhelmina Children's Hospital, Lundlaan 6, 3584EA, Utrecht, The Netherlands (E-mail: n.h.p. claessens-2@umcutrecht.nl).

$0022-5223 / \$ 36.00$

Copyright (C) 2019 by The American Association for Thoracic Surgery

https://doi.org/10.1016/j.jtcvs.2019.02.106
} 


\section{Abbreviations and Acronyms \\ $\mathrm{CA}=$ cerebral autoregulation \\ CHD = congenital heart disease \\ $\mathrm{COR}=$ correlation coefficient \\ $\mathrm{CPB}=$ cardiopulmonary bypass \\ etCO $\mathrm{C}_{2}=$ end-tidal carbon dioxide \\ FTOE = fractional tissue oxygen extraction \\ LCOS = low cardiac output syndrome \\ LVOTO $=$ left ventricular outflow tract obstruction \\ MABP $=$ mean arterial blood pressure \\ MRI = magnetic resonance imaging \\ NIRS = near-infrared spectroscopy \\ $\mathrm{rSO}_{2}=$ regional cerebral oxygen saturation \\ $\mathrm{SaO}_{2}=$ systemic arterial oxygen saturation \\ SVP = single ventricle physiology \\ TGA $=$ transposition of the great arteries \\ WMI = white matter injury}

Acquired brain injury is a common comorbidity in infants undergoing cardiac surgery for critical congenital heart disease (CHD). ${ }^{1}$ Neurodevelopmental sequelae occur in strikingly high incidences in survivors of open surgery for CHD early in life, ${ }^{2}$ with neonatal brain injury as one of the contributors. ${ }^{3}$ Over the last years, magnetic resonance imaging (MRI) studies have provided important insights into the nature and timing of brain injury in young infants with CHD. ${ }^{1}$ However, it remains difficult to identify infants at the highest risk of brain injury at an early stage.

The importance of optimal cerebral oxygenation and perfusion during intensive care stay and open surgery has been increasingly recognized in infants with CHD. ${ }^{4-7}$ Near-infrared spectroscopy (NIRS) is a noninvasive method to continuously monitor the regional cerebral oxygen saturation $\left(\mathrm{rSO}_{2}\right)$ at the bedside. Combining $\mathrm{rSO}_{2}$ with mean arterial blood pressure (MABP) is one of the methods to estimate cerebral autoregulation (CA) and the ability to maintain stable cerebral perfusion and oxygenation during fluctuations in blood pressure. ${ }^{8} \mathrm{CA}$ has not reached its maximum capacity in newborns and has been described to be more impaired in fetuses with $\mathrm{CHD},{ }^{9}$ in preoperative newborns with $\mathrm{CHD},{ }^{10}$ and during neonatal cardiopulmonary bypass $(\mathrm{CPB}){ }^{7,11}$ In infants with critical $\mathrm{CHD}$, the transition from prenatal to postnatal life, cardiac surgery with use of $\mathrm{CPB}$, and the intensive care period are accompanied by hemodynamic disturbances, which will be forwarded to the brain in case of immature CA. The association of bedside-measured indices of cerebral oxygenation and $\mathrm{CA}$ in this critical period with newly acquired ischemic brain injury has yet to be identified in infants with critical CHD.

The aim of this study was to assess intraoperative and postoperative indices of cerebral oxygenation and autoregulation using NIRS in infants undergoing cardiac surgery with the use of CPB for critical CHD, in relation to new postoperative ischemic brain injury.

\section{MATERIALS AND METHODS}

This is a prospective observational cohort study in infants with critical CHD who required cardiac surgery with the use of CPB at 30 days or less of life. Included cardiac defects were transposition of the great arteries (TGA), biventricular physiology with left ventricular outflow tract obstruction (LVOTO) requiring aortic arch reconstruction, and single ventricle physiology (SVP). All infants underwent cardiac surgery with the use of CPB within the first 30 days of life in the period of 2009 to 2012 (neuromonitoring and imaging for research purposes, SVP, and LVOTO) and 2016 to 2017 (neuromonitoring and imaging as part of standard clinical care, SVP, LVOTO, and TGA) at the Wilhelmina Children's Hospital in Utrecht, The Netherlands. Infants with a gestational age of 36 weeks or less, confirmed genetic disorder, or confirmed major congenital anomaly were excluded. The local medical ethical committee approved the study, and parental informed consent was obtained.

\section{Monitoring: Near-Infrared Spectroscopy and Amplitude-Integrated Electroencephalography}

NIRS monitoring was applied continuously from 6 hours before surgery to 48 hours after surgery in all infants. Preoperative and intraoperative NIRS were analyzed only in infants with deep hypothermia (ie, SVP and LVOTO). The INVOS 4100-5100 monitor (Medtronic, Boulder, Colo) was used, with bilateral (left and right fronto-parietal) small pediatric sensors (SomaSensor SPFB; Somanetics, Medtronic, Boulder, Colo). In parallel, amplitude-integrated electroencephalography registration was applied, which was scored for background pattern and ictal discharges. Abnormal brain activity was quantified as abnormal background pattern (burst suppression and lower) or ictal discharges.

\section{Monitoring: Vital Parameters}

Standard continuous physiologic parameters were measured using a patient monitor and stored with a $1 \mathrm{~Hz}$-sample rate on a personal computer for offline analysis using software developed in-house (Signalbase; University Medical Center Utrecht, Utrecht, The Netherlands): systemic arterial oxygen saturation $\left(\mathrm{SaO}_{2}\right)$, MABP using an indwelling arterial catheter (in the radial artery), and end-tidal carbon dioxide $\left(\mathrm{etCO} \mathrm{CO}_{2}\right.$ ). Preoperative and intraoperative parameters were stored and analyzed only for infants with deep hypothermia (ie, LVOTO or SVP).

\section{Indices of Cerebral Oxygenation and Autoregulation}

$\mathrm{rSO}_{2}$ is a representation of the oxygenated hemoglobin/total hemoglobin ratio. Because the arterial-venous ratio of cerebral blood volume is $25: 75, \mathrm{rSO}_{2}$ mainly reflects venous oxygen saturation of the brain. ${ }^{12}$ Fractional tissue oxygen extraction (FTOE) is an estimator of oxygen 


\section{Near infrared spectroscopy (NIRS)}

\begin{tabular}{|c|}
\hline Cerebral oxygenation \\
$\mathrm{rSO}_{2}=$ oxygenated $\mathrm{Hb} /$ total $\mathrm{Hb}$ \\
Fractional tissue oxygen extraction \\
$\mathrm{FTOE}=\left(\mathrm{SaO}_{2}-\mathrm{rSO}_{2}\right) / \mathrm{SaO}_{2}$ \\
Cerebral autoregulation $(\mathrm{CA}$, estimated) \\
$\mathrm{COR}=\mathrm{rSO}_{2} \sim \mathrm{MABP}$ \\
$\%$ time $\mathrm{COR} \geq 0.5$ (impaired $\mathrm{CA})$
\end{tabular}

$\mathrm{COR}=$ correlation between $\mathrm{rSO}_{2}$ and $\mathrm{MABP}$

MABP = mean arterial blood pressure

VIDEO 1. Video explaining brain circulation and ischemic brain injury in infants with critical CHD. Video available at: https://www.jtcvs.org/article/ S0022-5223(19)30584-7/fulltext.

extraction, calculated using the following equation: $\left(\mathrm{SaO}_{2}-\mathrm{rSO}_{2}\right) / \mathrm{SaO}_{2}$. The correlation between $\mathrm{rSO}_{2}$ and MABP (calculated as a correlation coefficient [COR]) was used as an estimator of CA (Video 1). A strong correlation between $\mathrm{rSO}_{2}$ and MABP suggests lack of CA, and COR 0.5 or greater was considered impaired CA. ${ }^{13}$ Examples of normal and impaired $\mathrm{CA}$ are shown in Figure 1. Epochs of 30 minutes (with 10-minute subperiods with $90 \%$ overlap) were selected preoperatively (night before surgery), intraoperatively (during $\mathrm{CPB}$, at moment of normothermia and at closure), and postoperatively $(1,6,12,18,24,36$, and 48 hours after surgery) to calculate $\mathrm{rSO}_{2}(\%)$, FTOE, and percentage of time with COR
0.5 or greater (time with signs of impaired CA, \%). Left and right measurements were averaged. Intraoperative measures were obtained only in infants with deep hypothermia (ie, LVOTO or SVP).

\section{Magnetic Resonance Imaging Scanning Protocol and Brain Injury Review}

Preoperative (between birth and surgery) and postoperative (5-10 days after surgery) MRI scans of the brain were performed on a 1.5T magnetic resonance system (2009-2012; Gyroscan ACS-NT, Philips Medical Systems, Best, The Netherlands) or a 3.0T magnetic resonance system (2016-2017; Achieva, Philips Medical Systems). Infants who required mechanical ventilation at the time of MRI received continuous sedation. Infants without mechanical ventilation were fed, swaddled in a vacuum cushion, and if necessary sedated with chloral hydrate (single dose $50-60 \mathrm{mg} / \mathrm{kg}$ ). All infants received 2 layers of hearing protection. During the MRI, oxygen saturation, heart rate, and respiratory rate were monitored. Both 1.5T and 3T MRI protocols included 3-dimensional T1-, T2-, axial diffusion-, and axial susceptibility-weighted sequences. All MRI scans were reviewed by 2 independent researchers for the presence of new postoperative brain injury: moderate-severe white matter injury (WMI) $(>3$ lesions $<2 \mathrm{~mm}$ or $\geq 2$ lesions $>2 \mathrm{~mm}$ ), focal infarction (white matter lesion $>2 \mathrm{~mm}$ or stroke with involvement grey matter), or parenchymal hemorrhage. Brain maturity was scored using the total maturation scoring system. ${ }^{14,15}$

\section{Perioperative Course}

All infants underwent cardiac surgery with the use of CPB. Infants with LVOTO underwent aortic arch reconstruction and if necessary an
$0 \%$ of time COR $\geq 0.5$

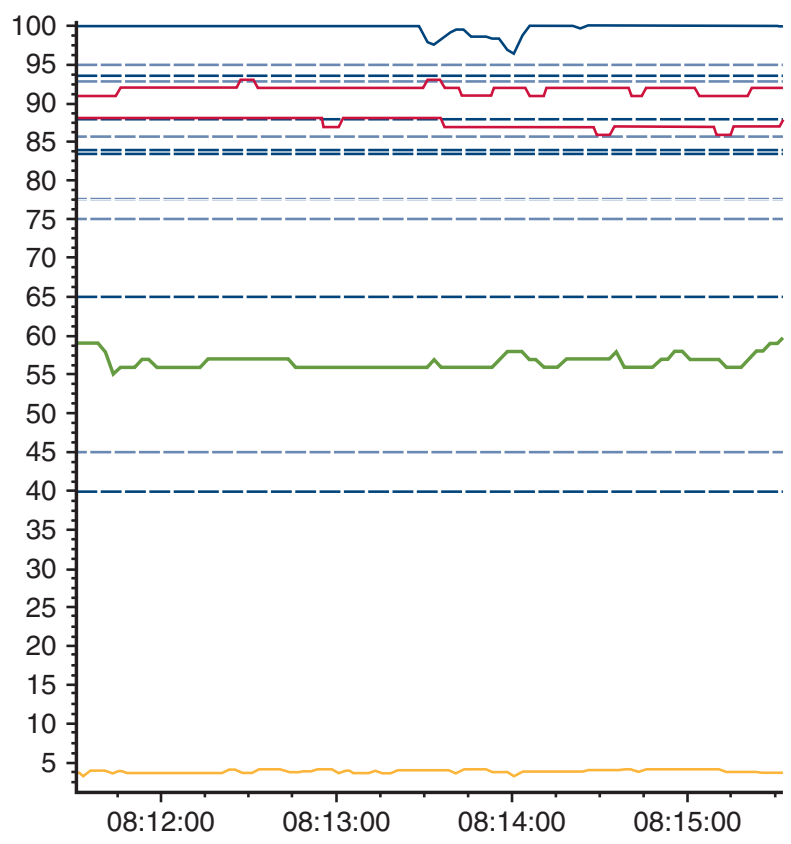

A

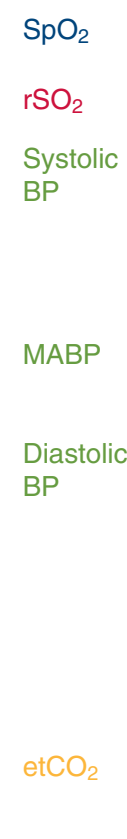

FIGURE 1. Monitoring of cerebral oxygenation and vital parameters. Four-minute epochs of cerebral and vital parameter registration are shown. The blue line indicates $\mathrm{SaO}_{2}$, green indicates MABP, with systolic and diastolic blood pressure indicated, red indicates $\mathrm{rSO}_{2}$, and yellow indicates etCO 2 . All parameters are plotted on the same $y$-axis scale with blue reference lines. A, The $\mathrm{rSO}_{2}$ and vital parameters registration of an infant 48 hours after surgery, with zero percent of time MABP-rSO $\mathrm{CO}_{2} \mathrm{COR} 0.5$ or greater. Stable $\mathrm{rSO} 2$ and MABP values are shown that are not correlated with each other. B, The registration of an infant the first night after surgery with $61 \%$ of time $\mathrm{MABP}_{-\mathrm{rSO}} \mathrm{COR}_{2} .5$ or greater. $\mathrm{MABP}$ is not stable over time, and when $\mathrm{MABP}_{\mathrm{increases}} \mathrm{rSO}_{2}$ increases. $\mathrm{COR}$, Correlation coefficient; $\mathrm{SpO}_{2}$, arterial oxygen saturation; $r \mathrm{SO}_{2}$, regional cerebral oxygen saturation; $B P$, blood pressure; $M A B P$, mean arterial blood pressure; et $\mathrm{CO}_{2}$, end-tidal carbon dioxide. 
additional Ross-Konno procedure or aortic valvotomy. Infants with SVP underwent the Norwood procedure or Damus-Kaye-Stansel procedure. Infants with LVOTO and SVP were cooled to a nasopharyngeal temperature of approximately $18^{\circ} \mathrm{C}$, and antegrade selective cerebral perfusion (SCP) or deep hypothermic circulatory arrest was chosen as the perfusion technique by standard double venous cannulation. Infants with TGA underwent the arterial switch operation with moderate hypothermia $\left(\sim 28^{\circ} \mathrm{C}\right)$. All infants received midazolam and morphine during the first 48 hours after surgery. Doses of midazolam and morphine were obtained from patient records for all postoperative time points. Low cardiac output syndrome (LCOS) was defined as lactate level greater than $4 \mathrm{mmol} / \mathrm{L}$ combined with $\mathrm{pH}$ less than 7.30 (at least 2 measurements with at least 30 minutes between the measurements).

\section{Statistics}

For statistical analysis, R v. 3.5.0 (R Foundation for Statistical Computing, Vienna, Austria) was used. Because most neonatal and pediatric intensive care units use pediatric (or neonatal) sensors, we decided to present the $\mathrm{rSO}_{2}$ values as obtained by our pediatric sensors. ${ }^{16}$ Descriptive statistics included means (standard deviation) for continuous parametric data, median (25th/75th centile) for nonparametric data, and counts (percentage) for categoric data. Kruskal-Wallis test, Mann-Whitney $U$ test, or chi-square test, where appropriate, was used to compare parameters between CHD groups. Paired $t$ test was performed to compare vital and cerebral parameters at different time points. A mixed-model approach was used (R, nlme package v. 3.1-137) to test the association between cerebral parameters and new postoperative brain injury. A total of 6 models were built with new WMI or new focal infarction as the dependent variable and $\mathrm{rSO}_{2}$, FTOE, or COR as the fixed variable, with the individual subject as a random slope factor. This approach can handle missing data correcting for multiple comparisons. On the basis of previous studies, ${ }^{1,17}$ LCOS and SCP were identified as risk factors for new WMI and new stroke, respectively, and therefore included in the mixed-model analysis. To explore the predictive ability of $\mathrm{rSO}_{2}, \mathrm{FTOE}$, and COR for new brain injury in multivariable logistic regression, an average value over the first 12 hours and over the entire postoperative period (1-48 hours) was calculated for each individual subject. Best subset selection analysis ( $R$, leaps package, v. 3.0) was used to identify the most optimal logistic regression model with clinical factors, $\mathrm{rSO}_{2}, \mathrm{FTOE}$, and $\mathrm{COR}$ as independent variables, and new WMI and new stroke as dependent variables. $P$ values were corrected for multiple comparisons using Bonferroni correction.

\section{RESULTS}

In total, 77 infants were included $(75 \%$ were male and $29 \%$ with postnatal diagnosis); 19 had TGA, 30 had LVOTO, and 28 had SVP. Infants with LVOTO and SVP underwent deep hypothermia with longer surgery and CPB

TABLE 1. Perioperative and magnetic resonance imaging characteristics for congenital heart disease subgroups

\begin{tabular}{|c|c|c|c|c|}
\hline A. Perioperative characteristics & TGA $(\mathbf{N}=19)$ & LVOTO $(\mathbf{N}=30)$ & $\operatorname{SVP}(\mathbf{N}=\mathbf{2 8})$ & $P$ value \\
\hline Age surgery, $d$ & $7(6 / 9)$ & $12(10 / 16)$ & $8(6 / 9)$ & $<.001$ \\
\hline Age surgery, postmenstrual wk & $40.6(39.5 / 41.2)$ & $41.4(40.3 / 42.0)$ & $40.3(39.1 / 41.1)$ & .02 \\
\hline Weight surgery, kg & $3.5(3.3 / 3.6)$ & $3.5(3.0 / 3.8)$ & $3.5(3.0 / 3.7)$ & .55 \\
\hline Duration surgery, min & $204(181 / 259)$ & $286(244 / 350)$ & $274(242 / 328)$ & $<.001$ \\
\hline Lowest temperature, ${ }^{\circ} \mathrm{C}$ & $28(26 / 30)$ & $21(20 / 22)$ & $20(19 / 22)$ & $<.001$ \\
\hline Duration $\mathrm{CPB}$, min & $131(116 / 148)$ & $162(123 / 220)$ & $167(142 / 185)$ & .03 \\
\hline Selective cerebral perfusion & - & $18(60)$ & $19(68)$ & $<.001$ \\
\hline LCOS* & $2(10)$ & $9(30)$ & $20(71)$ & $<.001$ \\
\hline Delayed sternal closure & $3(16)$ & $16(53)$ & $24(86)$ & $<.001$ \\
\hline Repeat thoracotomy* & $0(0)$ & $1(3)$ & $6(21)$ & .02 \\
\hline Cardiac arrest* & $0(0)$ & $0(0)$ & $2(7)$ & .17 \\
\hline Arrhythmias* & $6(32)$ & $7(23)$ & $6(21)$ & .71 \\
\hline Convulsions* & $0(0)$ & $2(7)$ & $4(14)$ & .19 \\
\hline Midazolam, cumulative dose at $48 \mathrm{~h}$ & $5.9(4.7 / 8.8)$ & $8.5(6.4 / 10.7)$ & $8.7(6.4 / 10.5)$ & .10 \\
\hline Morphine, cumulative dose at $48 \mathrm{~h}$ & $0.6(0.4 / 0.7)$ & $0.6(0.5 / 0.7)$ & $0.6(0.5 / 0.8)$ & .42 \\
\hline Mechanical ventilation, $\mathrm{h}$ & $81(52 / 89)$ & $180(120 / 360)$ & $315(208 / 435)$ & .01 \\
\hline Length of stay intensive care, $d$ & $4(4 / 6)$ & $7(5 / 11)$ & $12(8 / 15)$ & .01 \\
\hline Postoperative death & $1(5)$ & $0(0)$ & $2(7)$ & .35 \\
\hline B. Postoperative MRI findings & TGA $(N=18)$ & LVOTO $(\mathbf{N}=30)$ & $\operatorname{SVP}(\mathbf{N}=26)$ & $P$ value \\
\hline New moderate-severe WMI & $6(33)$ & $13(43)$ & $11(42)$ & .74 \\
\hline New focal infarction & $4(22)$ & $7(23)$ & $6(23)$ & .99 \\
\hline New parenchymal hemorrhage & $0(0)$ & $0(0)$ & $1(4)$ & $\mathrm{n} / \mathrm{a}$ \\
\hline Brain maturity score & $13(11 / 13)$ & $13(12 / 14)$ & $13(12 / 13)$ & .46 \\
\hline
\end{tabular}

For discontinuous parameters, $\mathrm{N}(\%)$ is shown. For continuous parameters, median with 25 th/75th centiles is shown. $P$ value for Kruskal-Wallis test or chi-square test between CHD subgroups is presented. A $P$ value less than .05 is indicated in bold. TGA, Transposition of the great arteries; LVOTO, left ventricular outflow tract; SVP, single ventricle physiology; $C P B$, cardiopulmonary bypass; $L C O S$, low cardiac output syndrome; $M R I$, magnetic resonance imaging; $W M I$, white matter injury; $n / a$, not available. *Present within the first 48 hours after surgery. 
time (Table 1). In addition, postoperative time on mechanical ventilation and midazolam dose were higher in those with LVOTO and SVP. Infants with SVP more often had postoperative LCOS with associated delayed sternal closure and repeat thoracotomy. Three patients died before postoperative MRI (1 TGA, 2 SVP).

\section{Intraoperative Indices of Cerebral Oxygenation and Autoregulation: Deep Hypothermic Circulatory Arrest Versus Selective Cerebral Perfusion}

Fifty-eight infants had aortic arch obstruction (LVOTO or SVP), of whom 21 had deep hypothermic circulatory arrest and 37 had SCP. Repair of TGA did not require deep hypothermia and was therefore not included in the intraoperative analysis.

When compared with the night before surgery, time with COR 0.5 or greater increased during CPB for all infants with LVOTO or SVP $(+33 \%$; $95 \%$ confidence interval, 17-49). Infants with $\mathrm{SCP}$ had higher $\mathrm{rSO}_{2}$ during $\mathrm{CPB}$ than infants with deep hypothermic circulatory arrest (64 vs $47 \%, P<.001)$ and less time with COR 0.5 or greater (34 vs $59 \%, P=.01$, Figure 2). Mean $\mathrm{SaO}_{2}$ during $\mathrm{CPB}$ was not different between infants with SCP and deep hypothermic circulatory arrest $(79 \%$ vs $78 \%, P=.90)$. Intraoperative $\mathrm{rSO}_{2}$, FTOE, and time with $\mathrm{COR} 0.5$ or greater were not associated with postoperative $\mathrm{rSO}_{2}$, FTOE, and time with COR 0.5 or greater, respectively (data not shown).

\section{Postoperative Indices of Cerebral Oxygenation and Cerebral Autoregulation: Comparison Between Congenital Heart Disease Groups}

$\mathrm{rSO}_{2}$ increased over the first 48 postoperative hours after surgery for all CHD groups. FTOE decreased over the postoperative period, mirroring the course of $\mathrm{rSO}_{2}$ (Figure 3). Absolute $\mathrm{rSO}_{2}$ was lowest in SVP at all postoperative time points. A notable increase in $\mathrm{rSO}_{2}$ was seen between 6 and 12 hours after surgery in all CHD groups, on average with a factor 1.4 (range, 1.1-2.4) and highest in SVP (TGA: 1.3, LVOTO: 1.4, SVP: 1.5, $P=.008)$

All infants demonstrated periods with COR 0.5 or greater (ie, sign of impaired CA) during the postoperative period (mean $15 \% \pm 19 \%$ of time). SVP showed significantly higher percentage of time with COR 0.5 or greater at all postoperative time points compared with TGA and from 6 hours onward compared with LVOTO (Figure 3). Time with COR 0.5 or greater did not significantly change during the first 48 hours after surgery for any CHD group. Time with COR 0.5 or greater was negatively associated with $\mathrm{rSO}_{2}(r=-0.30, P=.01)$, but not associated with FTOE $(r=0.01, P=.99)$ in linear regression analysis.

\section{Low Cardiac Output Syndrome and Indices of Cerebral Oxygenation and Autoregulation}

Postoperative LCOS was associated with lower average $\mathrm{rSO}_{2}$ and increased average time with COR 0.5 or greater (Table 2). In all infants, the onset of LCOS was within 12 hours after surgery. Increase in $\mathrm{rSO}_{2}$ between 6 and 12 hours was comparable between infants with and without postoperative LCOS (factor 1.45 vs 1.35 in TGA and LVOTO, respectively, $P=.14$; factor 1.56 vs 1.47 in SVP, respectively, $P=.50$ ). Other clinical variables such as postmenstrual age at time of surgery, sedatives, brain maturity score, and abnormal brain activity were not associated with average postoperative $\mathrm{rSO}_{2}$, FTOE, or time with COR 0.5 or greater (Table 2).

\section{Indices of Cerebral Oxygenation and Autoregulation in Relation to New Postoperative Brain Injury}

New postoperative WMI was seen in 30 infants $(41 \%)$, and new focal infarction was seen in 17 infants $(23 \%)$, with equal distribution across CHD groups (Table 1). New parenchymal hemorrhage was present in 1 infant and therefore not taken into account in further analysis.

A total of 513 postoperative measurements were included in mixed-model analysis, with LCOS and SCP included in the model for new WMI and new focal infarction, respectively. No relationship was seen in $\mathrm{rSO}_{2}$, FTOE, or COR with new WMI or new focal infarction (Table 3).

Best subset selection analysis (using averaged postoperative $\mathrm{rSO}_{2}, \mathrm{FTOE}$, and $\mathrm{COR}$ values for 1-12 hours and 1-48 hours) showed no significant associations of $\mathrm{rSO}_{2}$, FTOE, and COR with new postoperative WMI or focal infarction.

\section{Postoperative Vital Parameters and Indices of Cerebral Oxygenation and Autoregulation}

Postoperative $\mathrm{SaO}_{2}$ was significantly lower in SVP, where $\mathrm{MABP}$ and etCO $\mathrm{C}_{2}$ were comparable between $\mathrm{CHD}$ groups (Figure 4). $\mathrm{MABP}, \mathrm{SaO}_{2}$, and etCO $\mathrm{C}_{2}$ did not significantly change over the first 48 hours after surgery in any of the CHD groups. In Figure E1, postoperative associations of vital parameters with $\mathrm{rSO}_{2}$, FTOE, and time with $\mathrm{COR} 0.5$ or greater are presented for all CHD groups.

\section{DISCUSSION}

This study investigated intraoperative and postoperative indices of cerebral oxygenation and autoregulation in infants undergoing open surgery with CPB for critical CHD. Intraoperative and postoperative indices of cerebral oxygenation and CA as measured in our study were not independently related to new postoperative ischemic brain injury. In our study, we estimated CA by correlating $\mathrm{rSO}_{2}$ and MABP, which has been presented as a robust 
Deep hypothermic circulatory arrest
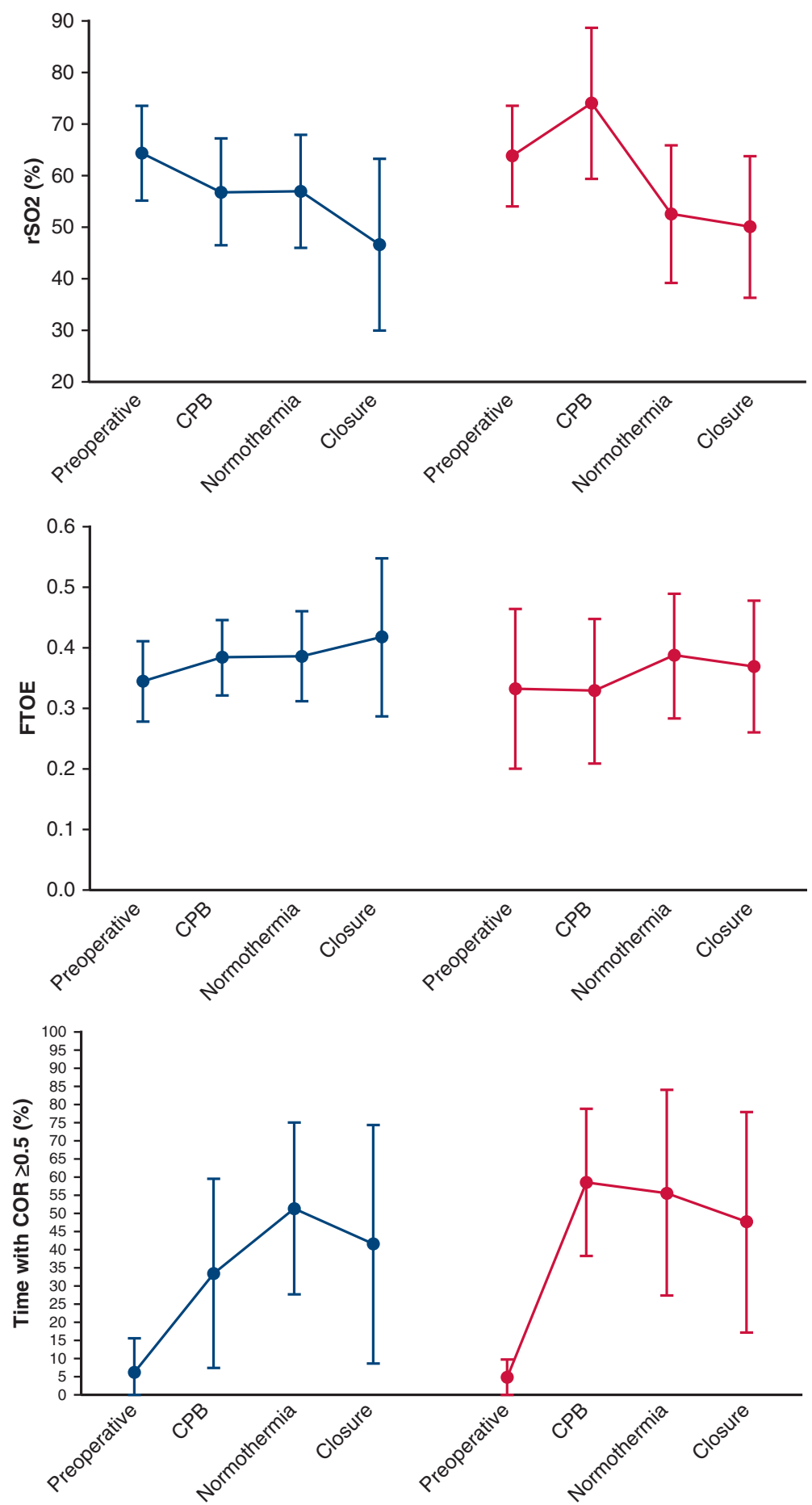

FIGURE 2. Trends in intraoperative indices of cerebral oxygenation and autoregulation. $\mathrm{rSO}_{2}, \mathrm{FTOE}$, and percentage of time with mean artial blood pressure-rSO $\mathrm{SO}_{2} \mathrm{COR} 0.5$ or greater for infants undergoing cardiac surgery with deep hypothermic circulatory arrest (left, blue) or selective cerebral perfusion (right, red). Only infants undergoing deep hypothermia for aortic arch reconstruction (ie, LVOTO and SVP, N = 58) were included in this analysis. Indices are shown from preoperative time point to $\mathrm{CPB}$ to moment of normothermia and to sternal closure. $r \mathrm{SO}_{2}$, Regional cerebral oxygen saturation; $\mathrm{CPB}$, cardiopulmonary bypass; FTOE, fractional tissue oxygen extraction; COR, correlation coefficient. 

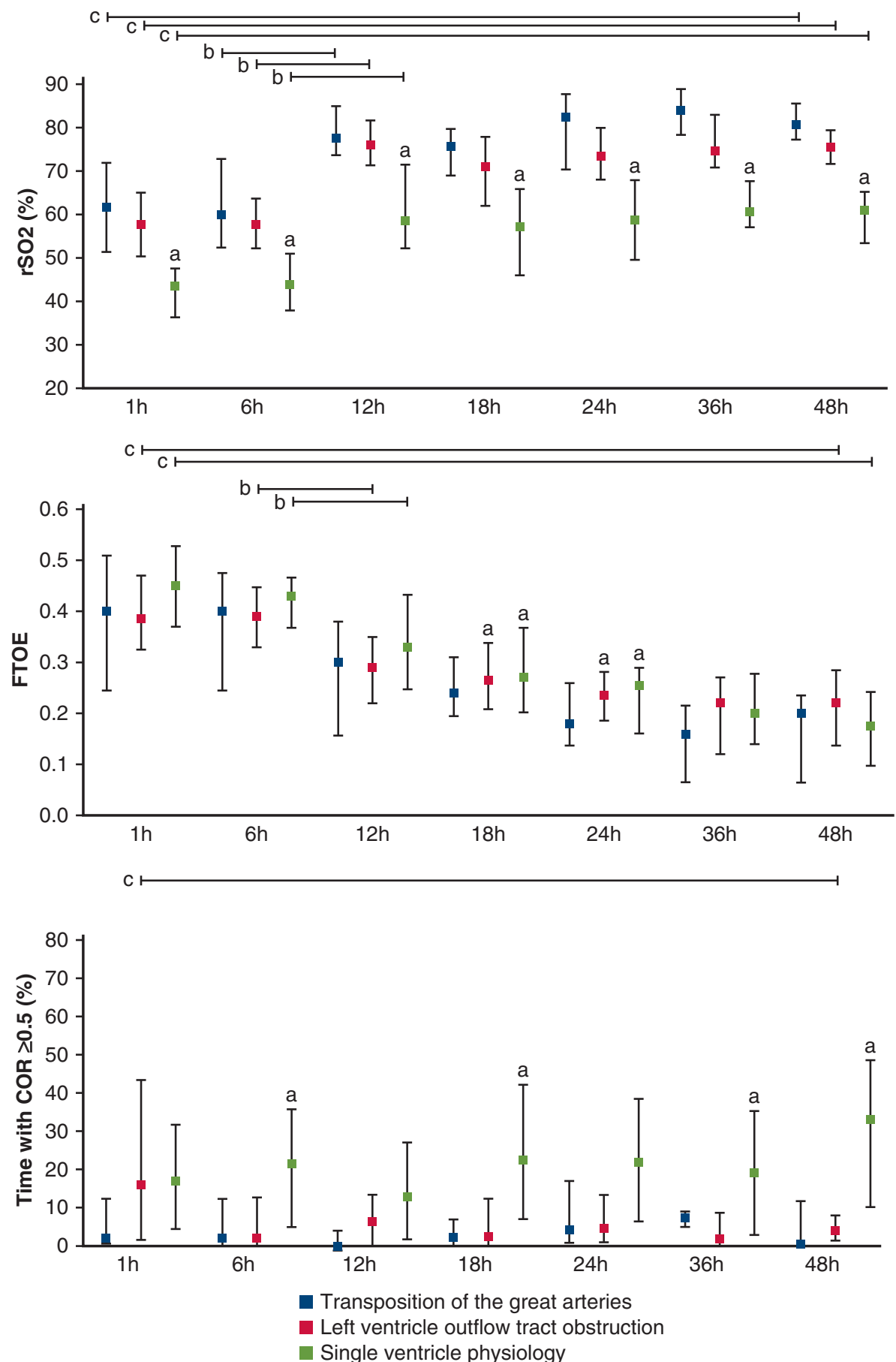

FIGURE 3. Trends in postoperative indices of cerebral oxygenation and autoregulation. $\mathrm{rSO}_{2}, \mathrm{FTOE}$, and percentage of time with mean artial blood pressure-rSO $\mathrm{SO}_{2}$ COR 0.5 or greater are presented at 7 time points during the first 48 hours after surgery for 3 CHD groups separately (TGA, LVOTO, and SVP). ${ }^{\mathrm{a}}$ The average value of this CHD group is significantly different from TGA as calculated by analysis of variance. ${ }^{\mathrm{b}}$ Indices measured at 6 hours and 12 hours after surgery were significantly different from each other. ${ }^{c}$ Indices measured at 1 hour and 48 hours after surgery were significantly different from each other. In all analyses, a $P$ value treshold of .008 was used (with Bonferroni correction for multiple tests per CHD subgroup). $r \mathrm{SO}_{2}$, Regional cerebral oxygen saturation; FTOE, fractional tissue oxygen extraction; COR, correlation coefficient.

index of CA in previous studies ${ }^{8,13}$; however, this is only one of the available methods to estimate CA. Infants with TGA, LVOTO, and SVP were investigated separately because of the different degree of disturbance in cerebral blood flow and blood oxygen content across these groups. 
TABLE 2. Association of postoperative indices of cerebral oxygenation and autoregulation with clinical variables

\begin{tabular}{|c|c|c|c|c|c|c|}
\hline \multirow[b]{2}{*}{ Clinical variables } & \multicolumn{2}{|c|}{$\mathbf{r S O}_{2}$} & \multicolumn{2}{|c|}{ FTOE } & \multicolumn{2}{|c|}{$\mathrm{COR} \geq 0.5$} \\
\hline & Correlation & $P$ value & Correlation & $P$ value & Correlation & $P$ value \\
\hline Postmenstrual age at surgery* & -0.03 & .80 & 0.15 & .34 & -0.13 & .42 \\
\hline Selective cerebral perfusion $\dagger$ & -0.18 & .16 & -0.05 & .76 & 0.25 & .12 \\
\hline Midazolam dose* & -0.01 & .94 & 0.13 & .46 & 0.23 & .19 \\
\hline $\operatorname{LCOS} \dagger$ & -0.55 & $<.001$ & 0.20 & .20 & 0.46 & .003 \\
\hline Brain maturity score* & 0.02 & .91 & 0.11 & .54 & 0.15 & .39 \\
\hline Abnormal brain activity $\dagger$ & -0.02 & .89 & 0.16 & .37 & 0.11 & .53 \\
\hline
\end{tabular}

Postoperative indices of cerebral oxygenation and autoregulation were averaged and associated with clinical factors; correlation coefficient $\mathrm{r}$ is presented with corresponding $P$ value. A $P$ value less than .015 with Bonferroni correction for multiple comparisons per variable is indicated by bold. $r S O 2$, Regional cerebral oxygen saturation; $F T O E$, fractional tissue oxygen extraction; COR, correlation coefficient; $L C O S$, low cardiac output syndrome. *Spearman's correlation coefficient. $\dagger$ Rank bi-serial correlation coefficient.

$\mathrm{rSO}_{2}$ is regulated by several mechanisms that include $\mathrm{CA}$ and cerebrovascular carbon dioxide and oxygen reactivity, but $\mathrm{rSO}_{2}$ is also dependent on systemic oxygen saturation, cardiac output, and brain metabolism. ${ }^{18-21} \mathrm{rSO}_{2}$ is considered a surrogate for cerebral blood flow, but only if $\mathrm{SaO}_{2}$, cerebral oxygen consumption, and cerebrovascular carbon dioxide and oxygen reactivity remain constant. ${ }^{8,20}$ Decrease in $\mathrm{rSO}_{2}$ immediately after $\mathrm{CPB}$ has been reported in neonates after the Norwood procedure for SVP ${ }^{19,22}$ and after the arterial switch operation for TGA. ${ }^{7,23}$ In our study, decreased $\mathrm{rSO}_{2}$ in the early postoperative period was demonstrated in all CHD groups, with a steady increase in $\mathrm{rSO}_{2}$ over the first 48 hours after surgery. This supports the hypothesis that early postoperative cerebral desaturation is a consequence of the higher energy demand and lower cardiac output after CPB, rather than the CHD-specific cardiac procedure or anatomic changes. $^{24}$

The results of our study revealed a notable increase in $\mathrm{rSO}_{2}$ between 6 and 12 hours after surgery in all CHD groups. This finding is in line with cardiac output reaching its nadir 6 to 12 hours after separation from CPB for cardiac repair. ${ }^{25}$ Low cardiac output decreases the ability to transport oxygenated blood to the brain and other organs, which can be quantified by higher lactate levels. ${ }^{26}$ Previous studies have shown an inverse relationship between lactate and $\mathrm{rSO}_{2} \cdot{ }^{27,28}$ In our study, postoperative LCOS (ie, high lactate with low $\mathrm{pH}$ ) was associated with lower $\mathrm{rSO}_{2}$.

CA is a compensatory mechanism with the ability to maintain cerebral perfusion and oxygenation relatively constant during changes in brain perfusion pressure. ${ }^{8} \mathrm{CA}$ is the property of arteries to constrict or dilate in response to respectively increase or decrease in pressure. ${ }^{29}$ Within the normal range of MABP, CA is expected to maintain stable cerebral blood flow. This mechanism is described as a plateau region in the static relationship between MABP and cerebral blood flow. Outside the plateau MABP thresholds, CA is lost and cerebral blood flow becomes linearly dependent on MABP. In neonates, the MABP thresholds of CA are unknown. ${ }^{8,21}$ In our study, we could not describe a clear trend between MABP and CA, which supports the hypothesis that MABP thresholds are individually determined in young infants. ${ }^{29}$

In this study, infants with SVP (and lowest $\mathrm{rSO}_{2}$ values) experienced more time with signs of impaired CA than infants with TGA or LVOTO. However, this population with the most complex and critical form of CHD is at risk of increased pulmonary flow after surgery (dependent on preferential flow through the shunt), potentially influencing the $\mathrm{rSO}_{2}$-MABP correlation independently from CA. ${ }^{19}$ Also, infants with SVP experience more often LCOS after surgery, which was associated with increased time with impaired CA in our study as well.

TABLE 3. Results of mixed-model analysis

\begin{tabular}{llll}
\hline Analysis & Dependent variable & \multicolumn{1}{c}{ Mixed-model terms } & $P$ value for F-test \\
\hline 1 & New WMI & CHD subgroup, $\mathrm{LCOS}, \mathrm{rSO}_{2}$, time point $\times \mathrm{rSO}_{2}$ & .12 \\
2 & New WMI & CHD subgroup, $\mathrm{LCOS}, \mathrm{FTOE}$, time point $\times$ FTOE & .39 \\
3 & New WMI & CHD subgroup, $\mathrm{LCOS}, \mathrm{COR}$, time point $\times \mathrm{COR}$ & .21 \\
4 & New focal infarction & $\mathrm{CHD}$ subgroup, $\mathrm{SCP}, \mathrm{rSO}_{2}$, time point $\times \mathrm{rSO}_{2}$ & .35 \\
5 & New focal infarction & CHD subgroup, SCP, FTOE, time point $\times$ FTOE & .97 \\
6 & New focal infarction & CHD subgroup, SCP, COR, time point $\times$ COR & .17 \\
\hline
\end{tabular}

A total of 6 models were built with new WMI or new focal infarction as dependent variable and $\mathrm{rSO}_{2}$, FTOE, or COR as the fixed variable, with the individual subject as a random slope factor. WMI, White matter injury; $\mathrm{CHD}$, congenital heart disease; $\mathrm{LCOS}$, low cardiac output syndrome; $r \mathrm{SO}_{2}$, regional cerebral oxygen saturation; FTOE, fractional tissue oxygen extraction; $C O R$, correlation coefficient; $S C P$, selective cerebral perfusion. 

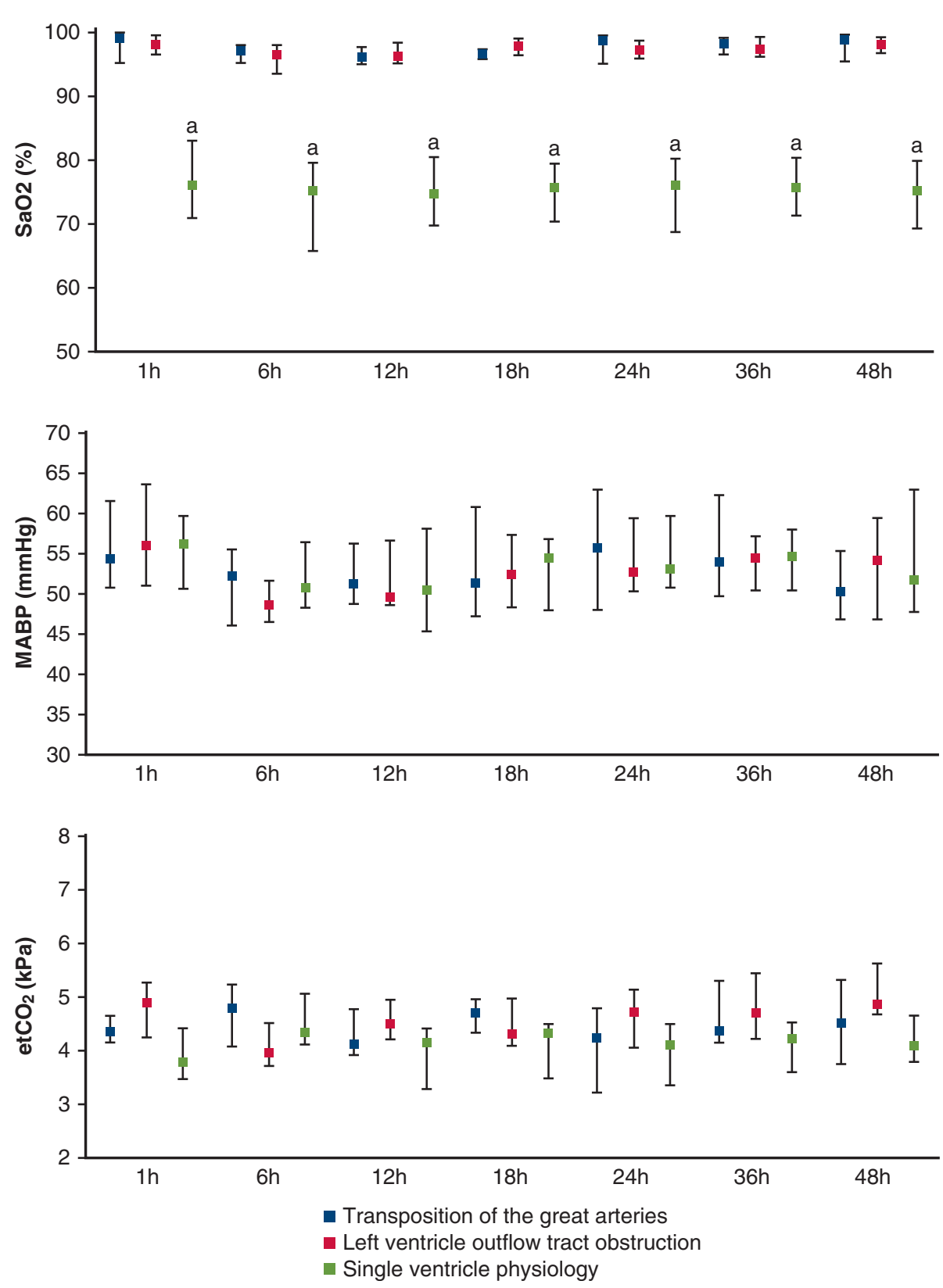

FIGURE 4. Trends in postoperative vital parameters. $\mathrm{SaO}_{2}, \mathrm{MABP}$, and et $\mathrm{CO}_{2}$ are presented at 7 time points during the first 48 hours after surgery for 3

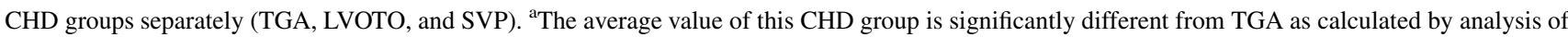
variance. In all analyses, a $P$ value treshold of .008 was used (with Bonferroni correction for multiple tests per $\mathrm{CHD}_{\text {subgroup). } \mathrm{SaO}}$, Systemic arterial oxygen saturation; $M A B P$, mean arterial blood pressure; etCO$_{2}$, end-tidal carbon dioxide.

In our study, infants with LVOTO and SVP showed a trend toward higher $\mathrm{rSO}_{2}$ with increasing etCO $\mathrm{C}_{2}$. In addition, SVP showed less time with COR 0.5 or greater (sign of impaired $\mathrm{CA}$ ) with increasing etCO $\mathrm{C}_{2}$. Two previous studies reported increased cerebral blood flow and autoregulatory capacity in ventilated infants when compared with nonventilated infants with CHD because of higher $\mathrm{CO}_{2}$ levels. ${ }^{10,30}$ Increased $\mathrm{CO}_{2}$ causes arterial cerebral vasodilatation, increasing cerebral blood supply, and subsequently cerebral oxygen delivery. The results of our study suggest that this phenomena is present in infants with arch obstruction (LVOTO and SVP) but not in infants with TGA, which was also seen in a previous study. ${ }^{7}$

Our study could not find an association of postoperative indices of cerebral oxygenation and CA with new postoperative WMI or focal infarction. A previous study including a part of our study population also failed to find an association between $\mathrm{rSO}_{2}$ and postoperative brain injury. ${ }^{31} \mathrm{WMI}$ is the 
most common type of brain injury after neonatal open surgery and most likely caused by acute fluctuations in cerebral perfusion and oxygenation. ${ }^{1}$ LCOS has been identified as a risk factor for WMI in infants with critical CHD. ${ }^{17}$ In our study, LCOS was associated with lower $\mathrm{rSO}_{2}$; however, no direct association of $\mathrm{rSO}_{2}$ with WMI could be seen. Focal infarction is most likely the result of thromboembolic events, and in the general neonatal population only large main artery strokes are reflected by (unilateral) increased $\mathrm{rSO}_{2}$ and FTOE ${ }^{32}$ In our cohort of infants with critical CHD, the majority of focal infarctions after CPB is limited to the basal ganglia and thalamus.

Future studies should reveal the long-term effects of prolonged low cerebral oxygenation after CPB. Especially in SVP, the brain might be conditioned to a continuous state of cerebral hypoxia. It is likely that this affects developing oligodendrocytes resulting in long-term brain immaturity, ${ }^{33,34}$ not directly visible as brain injury at postoperative MRI. Several studies showed an association between prolonged intraoperative and postoperative low cerebral oxygenation and poorer neurodevelopmental outcomes. ${ }^{4,5,35,36}$

\section{Study Limitations}

This study also has several limitations. First, $\mathrm{rSO}_{2}$ measured by NIRS represents a mixed saturation for $75 \%$ determined by the venous saturation. However, in response to hypoxia, the arterial contribution might increase as a consequence of cerebral arterial vasodilatation. Second, the NIRS monitor was not blinded in our clinical intensive care setting, which influences absolute $\mathrm{rSO}_{2}$ values. In other neonatal populations, it has been shown that $\mathrm{rSO}_{2}$ values are more stable and time with cerebral hypoxia is less when NIRS values are visible to the intensive care staff. ${ }^{37}$ Third, intraoperative registration of cerebral oxygenation and vital parameters is easily affected by surgical procedures, such as diathermy. It is also important to note that the type of NIRS device and sensors must be taken into account when interpreting absolute values of cerebral oxygenation. Pediatric sensors measure $\mathrm{rSO}_{2}$ values approximately $10 \%$ higher compared with adult sensors. ${ }^{16,38}$ No differences in the presence or extent of brain injury were seen between neonates scanned on a $1.5 \mathrm{~T}$ or $3 \mathrm{~T}$ MR scanner (both protocols included the same slice thickness).

\section{CONCLUSIONS}

Postoperative indices of cerebral oxygenation and autoregulation measured by NIRS do not independently predict new ischemic WMI or focal infarction in a clinical, prospective cohort of infants with different types of critical CHD. Lower cerebral oxygenation and increased time with signs of impaired CA are associated with the presence of LCOS and dependent on the CHD type. The results of this study suggest a complex causal chain and interplay of low
$\mathrm{rSO}_{2}$, LCOS, heart defect, and ischemic brain injury after $\mathrm{CPB}$ for critical CHD in infancy (Video 1). Further exploration of postoperative hemodynamics is required to identify cerebral oxygenation-related biomarkers enabling early intervention and prevention of ischemic brain injury.

\section{Conflict of Interest Statement}

Authors have nothing to disclose with regard to commercial support.

The authors thank Ben Nieuwenstein and Rene van de Vosse for their technical input in NIRS monitoring and analysis.

\section{References}

1. Claessens NHP, Kelly CJ, Counsell SJ, Benders M. Neuroimaging, cardiovascular physiology, and functional outcomes in infants with congenital heart disease. Dev Med Child Neurol. 2017;59:894-902.

2. International Cardiac Collaborative on Neurodevelopment Investigators. Impact of operative and postoperative factors on neurodevelopmental outcomes after cardiac operations. Ann Thorac Surg. 2016;102:843-9.

3. Claessens NHP, Algra SO, Ouwehand TL, Jansen NJG, Schappin R, Haas F, et al. Perioperative neonatal brain injury is associated with worse school-age neurodevelopment in children with critical congenital heart disease. Dev Med Child Neurol. 2018;60:1052-8.

4. Hoffman GM, Brosig CL, Mussatto KA, Tweddell JS, Ghanayem NS. Perioperative cerebral oxygen saturation in neonates with hypoplastic left heart syndrome and childhood neurodevelopmental outcome. J Thorac Cardiovasc Surg. 2013; 146:1153-64.

5. Hoffman GM, Ghanayem NS, Scott JP, Tweddell JS, Mitchell ME, Mussatto KA Postoperative cerebral and somatic near-infrared spectroscopy saturations and outcome in hypoplastic left heart syndrome. Ann Thorac Surg. 2017;103: 1527-35.

6. Andropoulos DB, Easley RB, Brady K, McKenzie ED, Heinle JS, Dickerson HA, et al. Changing expectations for neurological outcomes after the neonatal arterial switch operation. Ann Thorac Surg. 2012;94:1250-6.

7. Uebing A, Furck AK, Hansen JH, Nufer E, Scheewe J, Dutschke P, et al. Perioperative cerebral and somatic oxygenation in neonates with hypoplastic left heart syndrome or transposition of the great arteries. J Thorac Cardiovasc Surg. 2011; 142:523-30.

8. Caicedo A, Alderliesten T, Naulaers G, Lemmers P, van Bel F, Van Huffel S. A new framework for the assessment of cerebral hemodynamics regulation in neonates using NIRS. Adv Exp Med Biol. 2016;876:501-9.

9. Donofrio MT, Bremer YA, Schieken RM, Gennings C, Morton LD, Eidem BW, et al. Autoregulation of cerebral blood flow in fetuses with congenital heart disease: the brain sparing effect. Pediatr Cardiol. 2003;24:436-43.

10. Votava-Smith JK, Statile CJ, Taylor MD, King EC, Pratt JM, Nelson DP, et al. Impaired cerebral autoregulation in preoperative newborn infants with congenital heart disease. J Thorac Cardiovasc Surg. 2017;154:1038-44.

11. Smith B, Vu E, Kibler K, Rusin C, Easley RB, Andropoulos D, et al. Does hypothermia impair cerebrovascular autoregulation in neonates during cardiopulmonary bypass? Paediatr Anaesth. 2017;27:905-10.

12. Watzman HM, Kurth CD, Montenegro LM, Rome J, Steven JM, Nicolson SC Arterial and venous contributions to near-infrared cerebral oximetry. Anesthesiology. 2000;93:947-53.

13. Caicedo A, De Smet D, Naulaers G, Ameye L, Vanderhaegen J, Lemmers P, et al Cerebral tissue oxygenation and regional oxygen saturation can be used to study cerebral autoregulation in prematurely born infants. Pediatr Res. 2011;69: 548-53.

14. Licht DJ, Shera DM, Clancy RR, Wernovsky G, Montenegro LM, Nicolson SC, et al. Brain maturation is delayed in infants with complex congenital heart defects. J Thorac Cardiovasc Surg. 2009;137:529-37.

15. Childs AM, Ramenghi LA, Cornette L, Tanner SF, Arthur RJ, Martinez D, et al. Cerebral maturation in premature infants: quantitative assessment using MR imaging. AJNR Am J Neuroradiol. 2001;22:1577-82.

16. Alderliesten T, Dix L, Baerts W, Caicedo A, van Huffel S, Naulaers G, et al. Reference values of regional cerebral oxygen saturation during the first 3 days of life in preterm neonates. Pediatr Res. 2016;79:55-64. 
17. Beca J, Gunn JK, Coleman L, Hope A, Reed PW, Hunt RW, et al. New white matter brain injury after infant heart surgery is associated with diagnostic group and the use of circulatory arrest. Circulation. 2013; 127:971-9.

18. Tweddell JS, Hoffman GM, Fedderly RT, Ghanayem NS, Kampine JM, Berger S, et al. Patients at risk for low systemic oxygen delivery after the Norwood procedure. Ann Thorac Surg. 2000;69:1893-9.

19. Hoffman GM, Stuth EA, Jaquiss RD, Vanderwal PL, Staudt SR, Troshynski TJ, et al. Changes in cerebral and somatic oxygenation during stage 1 palliation of hypoplastic left heart syndrome using continuous regional cerebral perfusion. $J$ Thorac Cardiovasc Surg. 2004;127:223-33.

20. Cipolla MJ. The Cerebral Circulation. San Rafael, CA; 2009.

21. Peng T, Rowley AB, Ainslie PN, Poulin MJ, Payne SJ. Multivariate system identification for cerebral autoregulation. Ann Biomed Eng. 2008;36: 308-20.

22. Phelps HM, Mahle WT, Kim D, Simsic JM, Kirshbom PM, Kanter KR, et al. Postoperative cerebral oxygenation in hypoplastic left heart syndrome after the Norwood procedure. Ann Thorac Surg. 2009;87:1490-4.

23. Drury PP, Gunn AJ, Bennet L, Ganeshalingham A, Finucane K, Buckley D, et al. Deep hypothermic circulatory arrest during the arterial switch operation is associated with reduction in cerebral oxygen extraction but no increase in white matter injury. J Thorac Cardiovasc Surg. 2013;146:1327-33.

24. Toet MC, Flinterman A, Laar I, Vries JW, Bennink GB, Uiterwaal CS, et al. Cerebral oxygen saturation and electrical brain activity before, during, and up to 36 hours after arterial switch procedure in neonates without pre-existing brain damage: its relationship to neurodevelopmental outcome. Exp Brain Res. 2005;165: 343-50.

25. Wernovsky G, Wypij D, Jonas RA, Mayer JE Jr, Hanley FL, Hickey PR, et al. Postoperative course and hemodynamic profile after the arterial switch operation in neonates and infants. A comparison of low-flow cardiopulmonary bypass and circulatory arrest. Circulation. 1995;92:2226-35.

26. Wessel DL. Managing low cardiac output syndrome after congenital heart surgery. Crit Care Med. 2001;29:S220-30.

27. Chakravarti SB, Mittnacht AJ, Katz JC, Nguyen K, Joashi U, Srivastava S. Multisite near-infrared spectroscopy predicts elevated blood lactate level in children after cardiac surgery. J Cardiothorac Vasc Anesth. 2009;23:663-7.

28. Dodge-Khatami J, Gottschalk U, Eulenburg C, Wendt U, Schnegg C, Rebel M, et al. Prognostic value of perioperative near-infrared spectroscopy during neonatal and infant congenital heart surgery for adverse in-hospital clinical events. World J Pediatr Congenit Heart Surg. 2012;3:221-8.

29. Greisen G. Autoregulation of cerebral blood flow in newborn babies. Early Hum Dev. 2005;81:423-8.

30. Nagaraj UD, Evangelou IE, Donofrio MT, Vezina LG, McCarter R, du Plessis AJ, et al. Impaired global and regional cerebral perfusion in newborns with complex congenital heart disease. J Pediatr. 2015;167:1018-24.

31. Algra SO, Schouten AN, Jansen NJ, van Oeveren W, Haas F, Groenendaal F, et al Perioperative and bedside cerebral monitoring identifies cerebral injury after surgical correction of congenital aortic arch obstruction. Intensive Care Med. 2015; 41:2011-2.

32. De Vis JB, Petersen ET, Kersbergen KJ, Alderliesten T, de Vries LS, van Bel F, et al. Evaluation of perinatal arterial ischemic stroke using noninvasive arterial spin labeling perfusion MRI. Pediatr Res. 2013;74:307-13.

33. Dimitropoulos A, McQuillen PS, Sethi V, Moosa A, Chau V, Xu D, et al. Brain injury and development in newborns with critical congenital heart disease. Neurology. 2013;81:241-8.

34. Peyvandi S, De Santiago V, Chakkarapani E, Chau V, Campbell A, Poskitt KJ, et al. Association of prenatal diagnosis of critical congenital heart disease with postnatal brain development and the risk of brain injury. JAMA Pediatr. 2016; 170:e154450.

35. Kussman BD, Wypij D, Laussen PC, Soul JS, Bellinger DC, DiNardo JA, et al. Relationship of intraoperative cerebral oxygen saturation to neurodevelopmental outcome and brain magnetic resonance imaging at 1 year of age in infants undergoing biventricular repair. Circulation. 2010;122: 245-54.

36. Hoffman GM, Brosig CL, Bear LM, Tweddell JS, Mussatto KA. Effect of intercurrent operation and cerebral oxygenation on developmental trajectory in congenital heart disease. Ann Thorac Surg. 2016;101:708-16.

37. Hyttel-Sorensen S, Pellicer A, Alderliesten T, Austin T, van Bel F, Benders M, et al. Cerebral near infrared spectroscopy oximetry in extremely preterm infants: phase II randomised clinical trial. BMJ. 2015;350:g7635.

38. Dix LM, van Bel F, Baerts W, Lemmers PM. Comparing near-infrared spectroscopy devices and their sensors for monitoring regional cerebral oxygen saturation in the neonate. Pediatr Res. 2013;74:557-63.

Key Words: congenital heart defect, heart surgery, NIRS, cerebral oxygenation, MRI, brain injury 

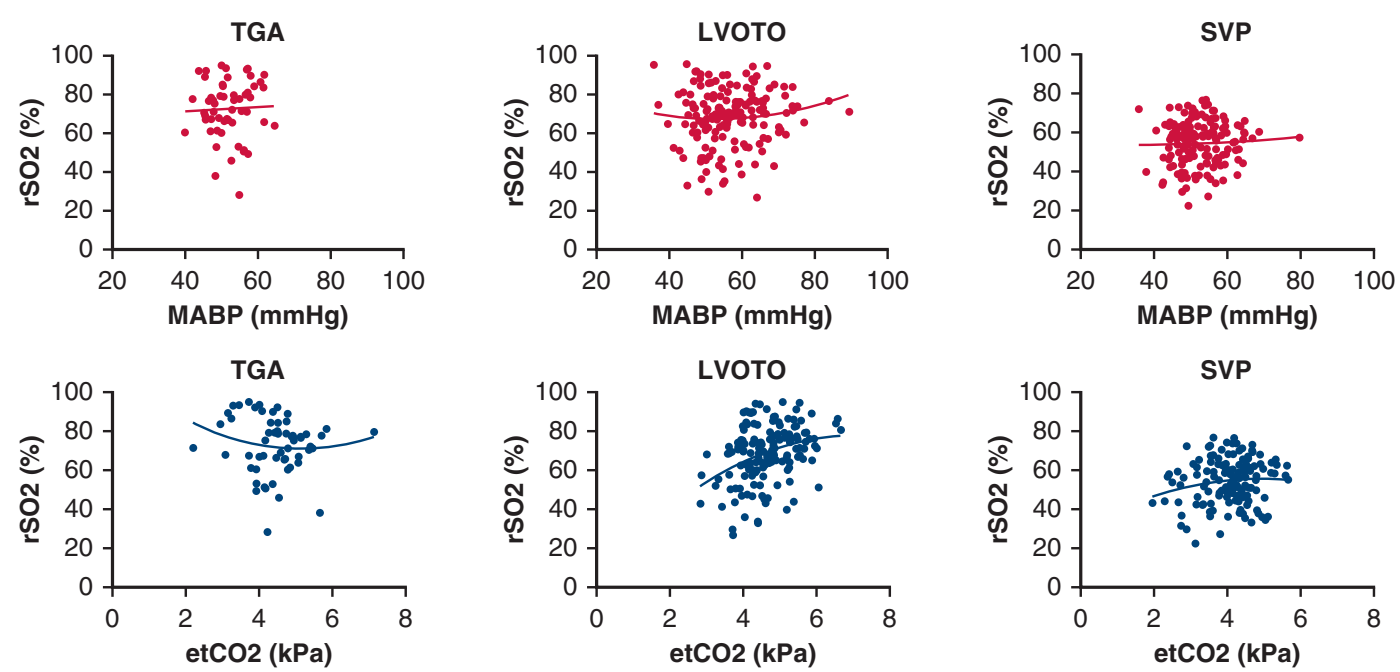

LVOTO
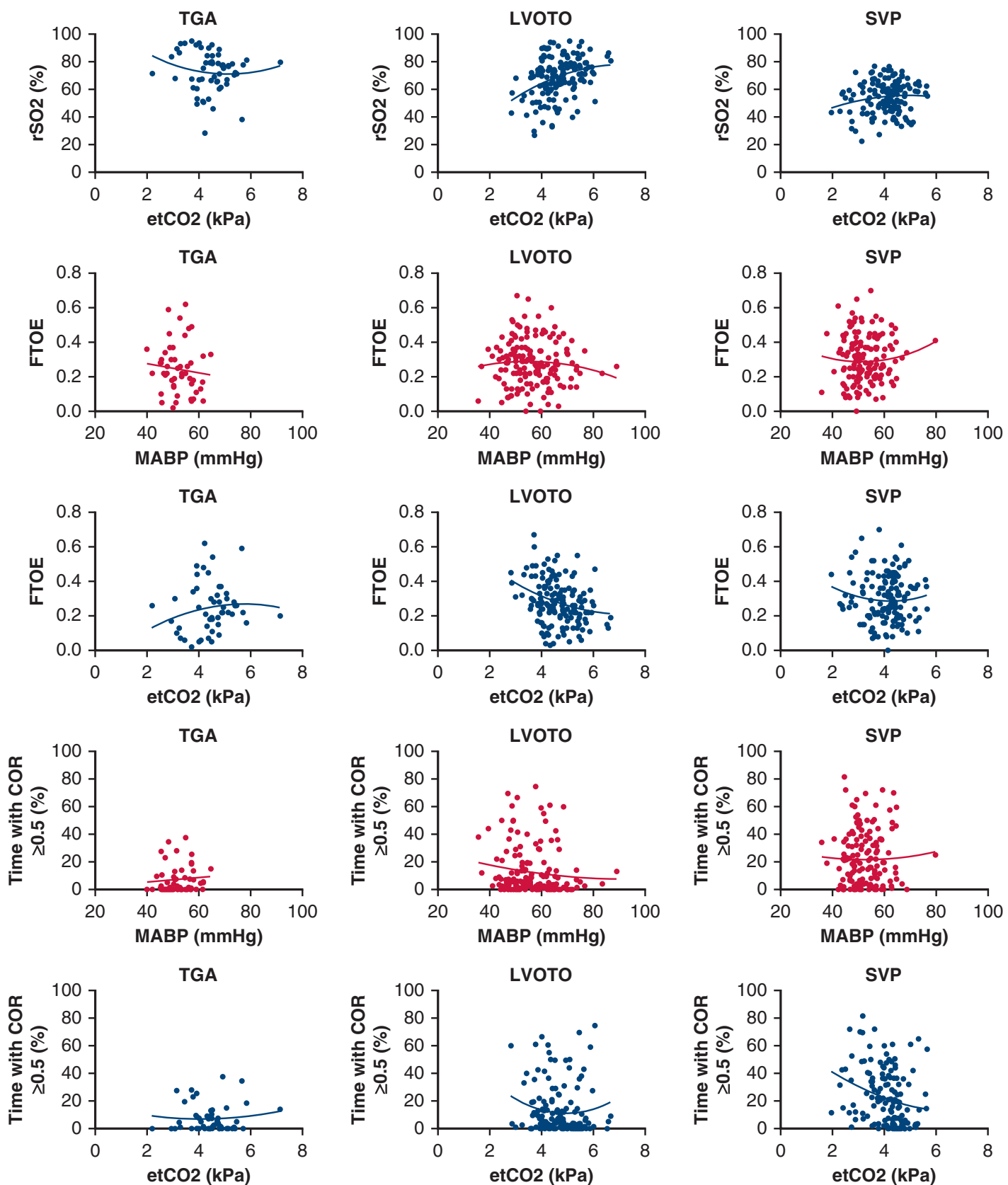

FIGURE E1. Postoperative indices of cerebral oxygenation and autoregulation in relation to vital parameters. $\mathrm{rSO}_{2}$, FTOE, and percentage of time with MABP-rSO $\mathrm{S}_{2} \mathrm{COR} 0.5$ or greater are presented graphically with linear or quadratic curve fitting against $\mathrm{MABP}$ and etCO $\mathrm{O}_{2}$ including all postoperative measurements. TGA, Transposition of the great arteries; $r \mathrm{SO}_{2}$, regional cerebral oxygen saturation; $M A B P$, mean arterial blood pressure; $L V O T O$, left ventricular outflow tract obstruction; $S V P$, single ventricle physiology; $e t C O_{2}$, end-tidal carbon dioxide; FTOE, fractional tissue oxygen extraction; $C O R$, correlation coefficient. 